\title{
Whirlpool sign
}

\author{
Suheil Artul, ${ }^{1}$ Yousif Nijim, ${ }^{2}$ Yousef Abu Rahmah, ${ }^{1}$ George Habib ${ }^{3}$
}

'Department of Radiology, EMMS Hospital, Bar Ilan University Faculty of Medicine, Nazareth, Israel

${ }^{2}$ Department of Neonatal, EMMS Hospital, Nazareth, Israel

${ }^{3}$ EMMS Hospital, Nazareth, Israel

\section{Correspondence to}

Dr Suheil Artul,

suheil_artul@hotmail.com

Accepted 16 April 2014

\section{DESCRIPTION}

A term female born through normal vaginal delivery after normal pregnancy started with parabolic bile stained vomit at the age of 4 days.

Abdomen X-ray was insignificant. Upper gastrointestinal study (UGI) showed complete obstructed third part of the duodenum suspecting duodenal web or volvulus with malrotation (figure 1). Ultrasound colour of the mid-abdomen showed whirlpool sign (figures 2 and 3) with definitive diagnosis of intestinal volvulus.

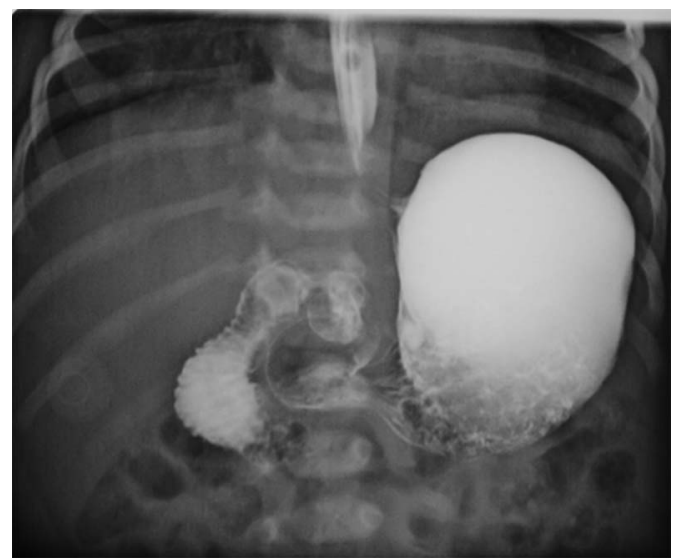

Figure 1 Upper gastrointestinal study showing the total obstruction of third part of the duodenum.
Malrotation with volvulus of mid-gut was found preoperatively but there was no intestinal necrosis. The duodenojejunal flexure was right positioned in relation to the spine. Ladd's bands were released by the surgical procedure. The baby did well in the postoperative period and was discharged from the hospital 1 week later in good condition.

Mid-gut volvulus causes partial or complete obstruction that can lead to ischaemia and necrosis of the involved bowel and therefore is a lifethreatening emergency. It usually occurs when there is a malrotation of the intestine. It is created when the superior mesenteric vein and the mesentery wrap around the superior mesenteric artery (SMA). ${ }^{1}$

It could be easily shown by transverse ultrasound colour of the abdomen as the whirlpool sign which shows concentric bowel loop with twisted concentric vessels around the SMA.

An important consequence of malrotation is malfixation of the intestines. Malfixation is inferred from malpositioning of the duodenojejunal junction or the caecum.

In general, the diagnosis of this potentially fatal disorder is made by means of UGI series documenting the position of the duodenojejunal flexure. However, sometimes it is difficult to locate this flexure specially when there is total obstruction due to volvulus, and in these cases ultrasound colour is mandatory and can easily show the whirlpool sign suggesting the definitive diagnosis of volvulus.

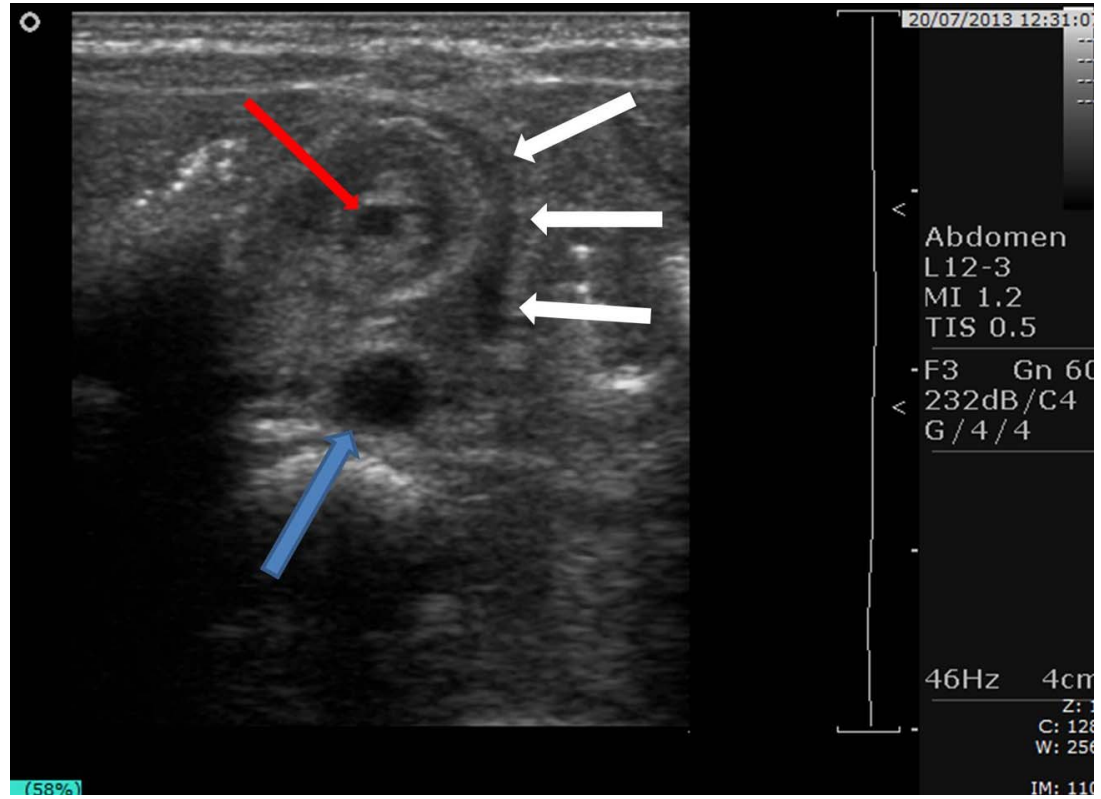

Figure 2 Ultrasound of the abdomen at the level of the duodenum showing the aorta (blue arrow), twisted superior mesenteric vein (white arrows) that stay to the left of the superior mesenteric artery (red arrow). 


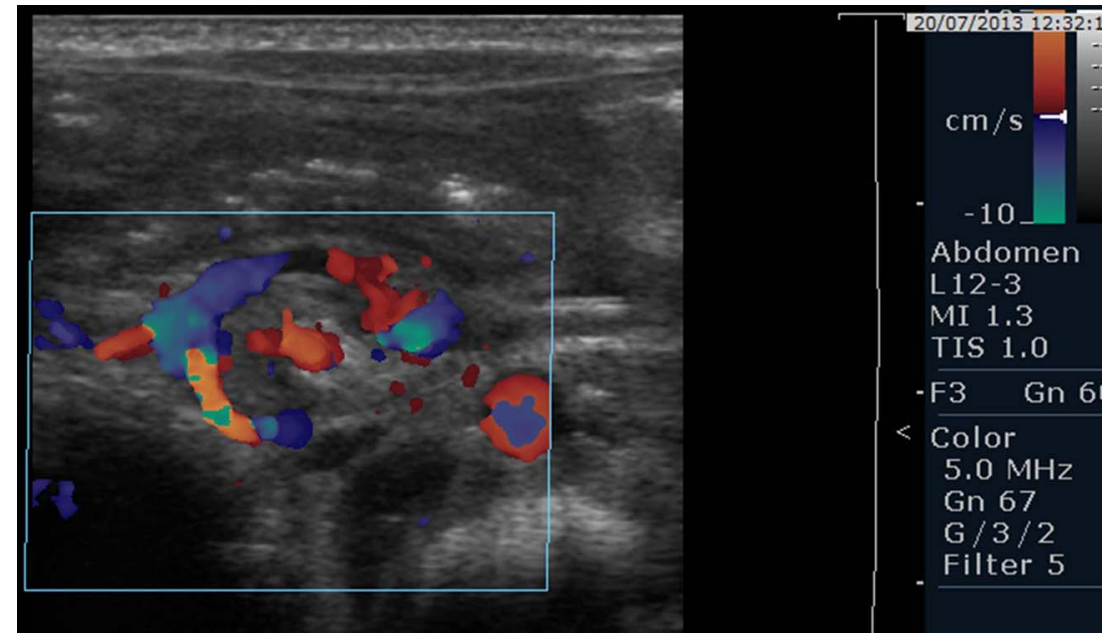

Figure 3 Ultrasound colour of the abdomen at the level of the duodenum showing the whirlpool sign.

The sensitivity and specificity of the 'whirlpool sign' for mid-gut volvulus caused by malrotation are $92 \%$ and $100 \%$, respectively. $^{2}$

\section{Learning points}

- Ultrasound colour should be performed in every baby with suspected intestinal obstruction.

- Whirlpool sign is pathognomonic of volvulus.

- When whirlpool sign is present there is no need for further investigation and indicates the need for immediate surgery.
Acknowledgements The authors thank Michael Shadi for his help in editing the figures.

Contributors All the authors worked together as a team in diagnosing this case and writing this draft.

Competing interests None.

Patient consent Obtained.

Provenance and peer review Not commissioned; externally peer reviewed.

\section{REFERENCES}

1 Epelman M. The whirlpool sign. Radiology 2006;240:910-11.

2 Huang YM, Wu CC. Whirl sign in small bowel volvulus. BMJ Case Rep. Published online: 13 Aug 2012. doi:10.1136/bcr-2012-006688

Copyright 2014 BMJ Publishing Group. All rights reserved. For permission to reuse any of this content visit http://group.bmi.com/group/rights-licensing/permissions.

BMJ Case Report Fellows may re-use this article for personal use and teaching without any further permission.

Become a Fellow of BMJ Case Reports today and you can:

- Submit as many cases as you like

- Enjoy fast sympathetic peer review and rapid publication of accepted articles

- Access all the published articles

- Re-use any of the published material for personal use and teaching without further permission

For information on Institutional Fellowships contact consortiasales@bmjgroup.com

Visit casereports.bmj.com for more articles like this and to become a Fellow 